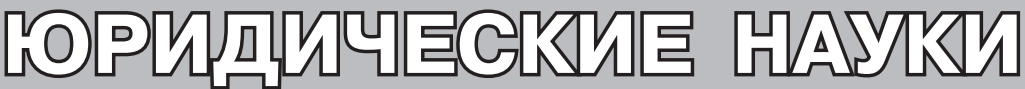

\section{Фимософия угомовно-испоннтельного права как метафеноменальная основа угомовно-исполнитемьной системы}

\begin{abstract}
В. Е. ЛАПШИН - профессор кафедры психологии личности и специальной педагогики Владимирского государственного университета им. А. Г. и Н. Г. Столетовых, профессор кафедры психологии и педагогики профессиональной деятельности Владимирского юридического института ФСИН России, доктор педагогических наук, кандидат юридических наук, доцент;
\end{abstract}

В. В. ШАХАНОВ - доцент кафедры теории и истории государства и права Владимирского филиала Российской академии народного хозяйства и государственной службы при Президенте Российской Федерации, доцент кафедры публично-правовых дисциплин факультета права и управления Владимирского юридического института ФСИН России, кандидат юридических наук

\section{Реферат}

Уголовно-исполнительная система не может быть охарактеризована как не требующая объяснений и обоснований очевидность. Подобно любой другой открытой системе она подвержена влиянию множества внешних и внутренних факторов. Степень и характер этого влияния не всегда можно познать и объяснить средствами аналитики теоретического уровня. Не все проблемные вопросы могут быть представлены в практической плоскости. Большой эвристический потенциал кроется в методологическом инструментарии философского уровня, который, по мнению авторов статьи, не получил широкого использования при познании сущности явлений и процессов, отражающих деятельность уголовно-исполнительной системы. Философия уголовно-исполнительного права является метафеноменальной основой деятельности в пенитенциарной сфере.

В статье рассматриваются традиционные проблемы уголовно-исполнительной системы, которые могут быть исследованы с применением философско-правового инструментария. Обращается внимание на необходимость формирования у сотрудников ФСИН России уголовно-правового мировоззрения и комплексного юридического мышления, что невозможно без освоения философского уровня знания о праве. Без философских оснований не может обойтись ни одна наука, поскольку их роль состоит в формировании интерпретационных схем, необходимых для уяснения сущности познаваемых явлений.

Цель статьи состоит в обосновании необходимости введения в образовательный процесс дисциплины «Философия уголовно-исполнительного права» либо рассмотрения вопросов философии уголовно-исполнительного права в рамках иных дисциплин, традиционно входящих в учебные планы высших учебных заведений ФСИН России. В числе проблемных вопросов, сопровождающих деятельность уголовно-исполнительной системы, которые можно наиболее полно рассмотреть в русле философско-правовых подходов, следует назвать переход от карательной функции пенитенциарной политики к охранительно-гуманитарной; необходимость морализации уголовно-исполнительного права; дуализм пенитенциарно-правовой политики; безопасность пенитенциарной системы; пределы либерализации уголовно-исполнительной политики и др. 
Ключевые слова: философия уголовно-исполнительного права; добродетель; философия права; уголовно-исполнительная система; метафеноменальная основа; синергетическая парадигма; морализация права.

12.00.01 - Теория и история права и государства; история учений о праве и государстве

\title{
The philosophy of penal law as a metafenomenal basis of the penal system
}

\begin{abstract}
V. E. LAPSHIN - Professor of the Department of Personality Psychology and Special Pedagogy of the Vladimir State University, Professor of the Department of Psychology and Pedagogy of Professional Activity of the Vladimir Law Institute of the Federal Penal Service of Russia, Dsc. in Pedagogics, PhD. in Law, Associate Professor;

V. V. SHAKHANOV - Associate Professor of the Department of Theory and History of State and Law of the Vladimir Branch of the Russian Academy of National Economy and Public Administration of President of the Russian Federation, Associate Professor of the Department of Public Law Disciplines of the Faculty of Law and Administration of the Vladimir Law Institute of the Federal Penal Service of Russia
\end{abstract}

\section{Abstract}

The penal system cannot be characterized as the evidence that does not require explanations and justifications. Like any other open system it is influenced by many external and internal factors. The degree and nature of this influence cannot always be known and explained by means of analytics of a theoretical level. Not all problematic issues can be presented in a practical way. A large heuristic potential lies in the methodological tools of the philosophical level, which according to the authors of the article did not receive wide use in understanding the essence of phenomena and processes reflecting the activities of the penal system. The philosophy of the penitentiary law is the metaphenomenal basis for activities in the penal sphere.

The article discusses the traditional problems of the penal system, which can be investigated using philosophical and legal tools. Attention is drawn to the need to form the criminal-legal outlook of the Russian Federal Penal Service staff and an integrated legal thinking that is impossible without mastering the philosophical level of knowledge of law. No science can do without philosophical grounds since their role consists in shaping the interpretative schemes necessary for understanding the essence of knowable phenomena.

The purpose of the article is to substantiate the need to introduce into the educational process the discipline "Philosophy of penal law" or to consider questions of the philosophy of penal law in the framework of other disciplines traditionally included in the curricula of higher educational institutions of the Federal Penal Service of Russia. Among the problematic issues that accompany the activities of the penal system, which can be most fully considered in the framework of philosophical and legal approaches, should be called the transition from the punitive function of the penal policy to protective and humanitarian; the necessity of moralizing penal law; dual penal legal policy; penal security; the limits of liberalization of penal policy, etc.

Keywords: philosophy of penal law; virtue; philosophy of law; penal system; metafenomenal basis; synergistic paradigm; moralization of law.

12.00.01 - Theory and history of law and state; history of studies of law and state

Работа в уголовно-исполнительной системе не входит в перечень наиболее востребованных специальностей на рынке труда. Об этом свидетельствует характерная для многих учреждений и органов ФСИН России проблема некомплекта штатной численности, сохраняющаяся несмотря на предпринимаемые государством усилия по социальной защите работников и сотрудников. В этой сфере существует еще много нерешенных вопросов, в числе которых можно назвать следующие: сотрудники находятся под колоссальным психологическим давлением; наблюдается увеличение числа напа- 
дений осужденных на персонал учреждений и др. Очевидно, что недостаточно акцентировать внимание только на важности и значимости работы в уголовно-исполнительной системе - необходимо донести ее философию до потенциального работника. В данной статье мы остановимся на традиционных проблемах уголовно-исполнительной системы, которые могут быть исследованы с использованием философско-правового инструментария.

Работа со спецконтингентом требует осознанного подхода к выбору данной профессии. Важно понимать не только суть и смысл этой трудовой деятельности, нужно осознать свою значимость в достижении целей уголовно-исполнительной системы. Неоценимую помощь в этом могло бы оказать изучение философии уголовно-исполнительного права. В таком предложении нет ничего экзотичного, что подтверждает практика организации научных мероприятий, освещающих вопросы смежных отраслей права. Так, философия уголовного права уже становилась центральной темой научнопрактических конференций, например, проведенной кафедрами уголовного и уголовно-исполнительного права в Саратовской государственной юридической академии 26 марта 2013 г. Появилась и научная литература, затрагивающая соответствующую тематику [14]. Следует внимательно изучить этот опыт и проводить подобные конференции и по философии уголовно-исполнительного права. Без философских оснований не может обойтись ни одна наука, поскольку их роль состоит в формировании интерпретационных схем, необходимых для уяснения сущности познаваемых явлений.

Наиболее сложным будет определиться с содержательной стороной подобного мероприятия. Тут следует выяснить, какие проблемные вопросы наиболее полно раскроют столь сложную тему, не получившую широкой реализации в системе ведомственного образования.

Центральными вопросами любой философии являются цель опосредуемой ею системы (онтология), пути достижения этой цели (гносеология) и ценности, которые преобладают в рамках данной системы (аксиология). Говоря в данной статье о философии, мы будем анализировать ее отдельный сегмент - философию права как самый высокий уровень его познания [5, с. 221].

Философия формирует мировоззрение. Философия уголовно-исполнительной системы должна быть ориентирована на по- нимание краеугольных камней соответствующей сферы общественной деятельности, становление уголовно-исполнительного мировоззрения. Узловые понятия философии уголовно-исполнительного права помогают глубже понять сущность и назначение уголовно-исполнительной системы, концептуализировать знания о ней.

Следуя известному тезису о том, что не стоит множить сущее без необходимости, считаем целесообразным включить раздел «Философия уголовно-исполнительного права» в дисциплину «Философия права», если она присутствует в учебном плане ведомственной образовательной организации. Здесь, однако, неизбежно встает вопрос определения содержания данного раздела, так как предмет философии права точно не определен и до сих пор в научной среде вызывает бурные дискуссии. Выходом из ситуации, когда набор подлежащих изучению учебных дисциплин сформулирован исчерпывающе и не может быть расширен, может стать рассмотрение вопросов философии уголовно-исполнительного права в рамках дисциплин «Философия», «Уголовно-исполнительное право» или «Теория государства и права». В последнем случае мы исходим из того, что консенсус в определении предметного поля теории государства и права в науке не достигнут и нередко философия права рассматривается как неотъемлемая часть теории права. Существуют и менее радикальные точки зрения. «В рамках теории государства и права не только возможно, но и желательно расширение и углубление философско-правовой проблематики», - отмечает О. В. Мартышин, настаивая тем не менее на том, что «философия, догматика и социология права - это не три раздела теории государства и права, не три части учебного курса, а три пласта, три подхода или метода исследования, которые присутствуют в разном соотношении почти в каждой теме» [8, с. 10]. В любом случае очевидно, что философско-правовая тематика тесно связана с теорией государства и права. Разночтения касаются лишь преобладания онтологических, гносеологических либо аксиологических начал философско-правовой составляющей в этом симбиозе.

Используя философско-правовой инструментарий, можно более рельефно обосновать необходимость осуществляемого перехода от карательной функции пенитенциарной политики к охранительно-гуманитарной, реализуемой на основе принципов 
уважения прав человека и законности. Наиболее подходят для данной цели темы, традиционно рассматриваемые в рамках философии права: соотношение права и морали, нравственные ценности в праве. Подобными вопросами задавались и классики философии права. Так, Б. Н. Чичерин отмечал, что несмотря на понимание содержательной стороны добра и зла, нравственных и безнравственных действий, человек «далеко не всегда сообразует свое поведение с этими понятиями; весьма часто он уклоняется от того, что он сам признает добром, и следует тому, что он признает злом» [15, с. 163].

В отношениях с осужденными работники и сотрудники уголовно-исполнительной сисетмы должны проявлять добродетель, которая заключается в способности «воздерживать свои влечения и подчинять их общему закону» [15, с. 196]. Эксплуатируемый в этом понятийном поле в рамках юриспруденции термин «законность», к сожалению, не обладает факторами побудительного свойства: он весьма сух и не оказывает большого влияния на эмоциональную сферу, что, безусловно, необходимо для формирования устойчивого желания следовать в заданном направлении. Очевидно, что понятия «добродетель» и «законность» не совпадают, а лишь частично пересекаются. Добродетель, скорее, тяготеет к морали. Тем не менее регулятивный потенциал этого основательно подзабытого термина мог бы быть востребован в сфере исполнения уголовных наказаний. Если выстроить понятийный ряд морально-правовых категорий, то добродетель в праве можно было бы расположить где-то посредине между законом как отражением минимума нравственности и моралью (нравственностью). Актуально использование данного термина и в связи с нарастающей в юридической науке тенденцией устремления в сторону морализации права. Если брать собственно правовую сферу, то термин «добродетель» может конкурировать с понятиями «добрые нравы» и «добрая совесть». Практику применения этих категорий в юриспруденции анализировал более ста лет назад И. А. Покровский применительно к проблемам гражданского права [10, с. 253-258]. Своеобразным отголоском исканий начала прошлого столетия можно считать включение в Гражданский кодекс Российской Федерации в 2012 г. принципа добросовесности сторон (п. 3, 4 ст. 1 ГК РФ). Полагаем, что право не может быть морально только в отдельных своих отраслях. Морализировать необходимо каждую отрасль права, в том числе и уголовно-исполнительное право.

Сложность реализации пенитенциарно-правовой политики заключается в своеобразном дуализме. Необходимо, с одной стороны, проявлять добродетель, а с другой - жестко реагировать на противоправное поведение осужденных в местах лишения свободы. Крайней реакцией на нежелание определенной категории заключенных вставать на путь исправления можно считать общественный запрос на ужесточение пенитенциарно-правовой политики [7, с. 109]. Этому способствует и периодическая публикация в СМИ информации о комфортных условиях содержания некоторых заключенных, являвшихся в недавнем прошлом высокопоставленными чиновниками либо совершивших резонансные преступления.

Необходимость существования любого дуализма красноречиво можно обосновать при помощи парных философских категорий: необходимость и случайность (обусловленные, например, обстоятельствами места, времени, действия), явление и сущность, действительность и возможность, конкретное и абстрактное, форма и содержание и др. Например, В. Г. Швыдкий, умело используя философские категории «форма» и «содержание», раскрывает восприятие подозреваемым пребывания в СИЗО как наказание за предшествующее поведение, поскольку «действительное содержание процессуальной формы противоречит ее сущности, которая не предполагает высокой степени тяжести конкретных условий жизни и быта в СИЗО, вызывающих страдание человека» [16, с. 23]. Е. В. Свинин рассматривает случайность правомерного поведения как сигнал о необходимости внесения изменений в правовое регулирование [12, с. 21]. Это положение справедливо и в отношении уголовно-исполнительного законодательства.

Данный философский подход получил свое развитие и в теории права, где стремящиеся друг к другу крайние явления и процессы объективной государственно-правовой реальности, имеющие общую основу и образующие синергетический эффект, рассматривают в качестве парных юридических категорий [11, с. 73-74].

Вопросы безопасности пенитенциарной системы могут быть освещены в рамках традиционного философско-правового блока «Личность, общество, государство» [9, с. 312-350]. Режим безопасности должен распространяться на всех участников уго- 
ловно-исполнительных правоотношений: персонал учреждений уголовно-исполнительной системы должен работать в безопасных условиях, осужденные должны отбывать наказание, не испытывая необоснованных притязаний как со стороны администрации, так и со стороны других осужденных.

В структуру вышеуказанного блока необходимо включить рассмотрение вопроса о пределах либерализации уголовно-исполнительной политики. Либерализация не должна граничить со вседозволенностью. Не следует забывать о том, что одним из основных средств исполнения наказания является определенный правовой и фактический режим. Перегибы в сторону либерализации приведут к ощущению вседозволенности и будут детерминировать рост преступности. Да и общественный запрос на либерализацию, на наш взгляд, себя исчерпал. Либеральные ценности вступают в противоречие с ценностями социально ориентированного законодательства. Либерализация все чаще в глазах обывателя ассоциируется с хаосом, а не со свободой в рамках, за которыми следуют определенные ограничения.

Вопрос правового воспитания осужденных целесообразно освещать на фоне осмысления взаимодействия естественного и позитивного права, о чем мы ранее уже писали [4, с. 15]. Логично это предпринять в разделе, посвященном изучению проблем правосознания, правовой культуры и правовой идеологии [13, с. 392-550]. С использованием философско-правовых средств более глубокое понимание может обрести и проблема деформации профессионального правосознания сотрудников уголовно-исполнительной системы.

Вопросы философии уголовно-исполнительного права будут более доступно раскрываться в симбиозе с вопросами философии уголовного права. Не углубляясь в эту весьма обширную тематику, отметим, например, безусловную актуальность анализа философско-правовых аспектов наказания [2]. Постановка данной проблемы будет отвечать потребностям как уголовного, так и уголовно-исполнительного права. Одним из важных аспектов наказания является вопрос справедливости его назначения. Справедливость имеет разнообразные формы (воздающая справедливость, нравственная справедливость, правовая справедливость, калькулирующая справедливость, упорядочивающая справедливость, идентифицирующая справедливость и др.), проанализировать которые в правовой реальности возможно только с использованием философско-правовых подходов [6, с. 205-211].

Дискурсивным фоном при освещении вопросов философии уголовно-исполнительного права может служить парадигмальная проблематика. Право не свободно от парадигмального мышления. Полагаем, что в рамках философии уголовно-исполнительного права ждет своего осмысления возможность использования познавательного потенциала синергетической парадигмы. Существует объективная необходимость создания синергетической модели функционирования и развития уголовно-исполнительной системы, определения ее энтропийного оптимума. Любая система функционирует в условиях определенного хаоса, который при нескольких условиях порождает порядок. Посредством синергетического методологического инструментария может быть осмыслена и вышеобозначенная проблема деформации профессионального сознания сотрудников уголовно-исполнительной системы, поскольку существенной системно-структурной характеристикой данного вида профессионального сознания является наличие в нем энтропии. Соглашаясь с В. А. Груниной, отметим, что «потенциал синергетики в практической плоскости в рамках проблемы повышения эффективности правового регулирования общественных отношений остается преимущественно незадействованным» [3, с. 3]. В ходе анализа многих вопросов, актуальных для уголовно-исполнительной системы, могли бы быть использованы и парадигмы правопонимания.

Одним из центральных в философии права является положение о свободе [1, с. 82]. Не вызывает сомнения важность данной темы и для философии уголовно-исполнительного права. Свобода здесь имеет множество граней и не замыкается исключительно на окончании отбывания наказания: значимыми являются аспекты свободы совести, свободы вероисповедания (ст. 14 УИК РФ), ограничения свободы (гл. 8 УИК РФ). Свобода должна быть рассмотрена исключительно в философском аспекте - как осознанная необходимость. Многие проявления ее не поименованы в действующем законодательстве, но их ценность от этого не уменьшается. Возможность выбора при соблюдении определенных требований (например, законных требований администрации, принятых в обществе нравственных норм поведения и др.) - это тоже свобода. В русле философско-правового понимания положений о свободе можно объяснять важность добро- 
совестного исполнения своих обязанностей как необходимой предпосылки для реализации предоставленных законом прав.

Многие вопросы философии уголовноисполнительного права имеют метафеноменальное значение для уголовно-исполнительной системы. Они устанавливают границы познания явлений правовой действительности и указывают направление поиска. Этим определяется их теоретическая и методологическая ценность. С их помощью можно повысить качество восприятия явлений правовой действительности уголовно-исполнительной направленности, обосновать необходимость совершенствования действующей правовой системы. Без их изучения невозможно формирование комплексного юридического мышления, которым должен обладать сотрудник ФСИН России.

Философия уголовно-исполнительного права нуждается в дальнейшей разработке, а полученные в результате этого процесса знания должны быть доступны работникам и сотрудникам уголовно-исполнительной системы.

\section{СПИСОК ЛИТЕРАТУРЫ}

1. Алексеев С. С. Философия права. М., 1999. 336 с.

2. Байтеева М. В. Философско-правовые аспекты наказания // Вестн. Владимир. юрид. ин-та. 2006. № 1. С. $23-27$. 3. Грунина В. А. Синергетические основы правового регулирования : автореф. дис. ... канд. юрид. наук. Владимир, 2006. $22 \mathrm{c}$

4. Лапшин В. Е., Шаханов В. В. Правовое воспитание осужденных: поиск новых подходов // Вестн. ин-та: преступление, наказание, исправление. 2018. № 1 (41). С. 13-18

5. Лейст О. Э. Сущность права. Проблемы теории и философии права. М., 2002. 288 с

6. Малахов В. П. Философия права : учеб. пособие. М., 2002. 448 с.

7. Малько А. В., Ромашов Р. А., Тимофеева Е. А. Пенитенциарно-правовая политика России: конституционные основы : обзор материалов всерос. круглого стола (Самара, 12 декабря 2013 г.) // Гос-во и право. 2014. № 12. C. $106-114$

8. Мартышин О. В. Общетеоретические юридические науки и их соотношение // Гос-во и право. 2004. № 7. С. 5-11. 9. Мартышин О. В. Философия права : учеб. для магистров. М., 2017. 352 с.

10. Покровский И. А. Основные проблемы гражданского права. М., 2001. 354 с.

11. Рудаков А. А. Парные юридические категории: теория прав и обязанностей : моногр. М., 2017. 232 с.

12. Свинин Е. В. Необходимость и случайность как выражение закономерностей правовой действительности : автореф. дис. ... канд. юрид. наук. Владимир, 2006. 26 с.

13. Философия права. Курс лекций : учеб. пособие : в 2 т. / отв. ред. М. Н. Марченко. М., 2018. Т. 1. 552 с.

14. Философия уголовного права / сост. д-р юрид. наук, проф. Ю. В. Голик, А. Ю. Голик ; ред. и вст. ст. д-ра юрид. наук, проф. Ю. В. Голика. СПб., 2004. 348 с.

15. Чичерин Б. Н. Философия права. 2-е изд., испр. М., 2011. 344 с.

16. Швыдкий В. Г. Кара - качество уголовного наказания // Гос-во и право. 2006. № 4. С. 21-28.

\section{REFERENCES}

1. Alekseev S. S. Filosofiya prava [Philosophy of law]. Moscow, 1999. 336 p. (In Russ.)

2. Bajteeva M. V. Filosofsko-pravovye aspekty nakazaniya [Philosophical and legal aspects of punishment]. Vestn. Vladimir. yurid. in-ta - Bulletin of the Vladimir Law Institute. 2006. Iss. 1. P. 23-27. (In Russ.)

3. Grunina V. A. Sinergeticheskie osnovy pravovogo regulirovaniya : avtoref. dis.... kand. yurid. nauk [Synergetic foundations of legal regulation : the author's abstract of the diss. ... PhD. in Law]. Vladimir, 2006. 22 p. (In Russ.).

4. Lapshin V. E., SHahanov V. V. Pravovoe vospitanie osuzhdennyh: poisk novyh podhodov [Legal education of convicts: the search for new approaches]. Vestn. in-ta: prestuplenie, nakazanie, ispravlenie - Bulletin of the Institute: crime, punishment, correction. 2018. Iss. 1 (41). P. 13-18. (In Russ.).

5. Lejst O. EH. Sushchnost' prava. Problemy teorii i filosofii prava [The essence of law. Problems of the theory and philosophy of law]. Moscow, 2002. 288 p. (In Russ.).

6. Malahov V. P. Filosofiya prava : ucheb. posobie [Philosophy of Law : tutorial]. Moscow, 2002. 448 p. (In Russ.).

7. Mal'ko A. V., Romashov R. A., Timofeeva E. A. Penitenciarno-pravovaya politika Rossii: konstitucionnye osnovy : obzor materialov vseros. kruglogo stola (Samara, 12 dekabrya 2013 g.) [Penal-legal policy of Russia: constitutional bases : review of materials of the All-Russian round table (Samara, December 12, 2013)]. Gos-vo i pravo - State and law. 2014. Iss. 12. P. 106-114. (In Russ.).

8. Martyshin O. V. Obshcheteoreticheskie yuridicheskie nauki i ih sootnoshenie [General theoretical legal sciences and their relationship]. Gos-vo i pravo - State and law. 2004. Iss. 7. P. 5-11. (In Russ.)

9. Martyshin O. V. Filosofiya prava : ucheb. dlya magistrov [Philosophy of Law : textbook for masters]. Moscow, 2017. 352 p. (In Russ.).

10. Pokrovskij I. A. Osnovnye problemy grazhdanskogo prava [The main problems of civil law]. Moscow, 2001. 354 p. (In Russ.).

11. Rudakov A. A. Parnye yuridicheskie kategorii: teoriya prav i obyazannostej : monogr. [Paired legal categories: theory of rights and obligations : monograph]. Moscow, 2017. 232 p. (In Russ.).

12. Svinin E. V. Neobhodimost' i sluchajnost' kak vyrazhenie zakonomernostej pravovoj dejstvitel'nosti : avtoref. dis. ... kand. yurid. nauk [Necessity and chance as an expression of the laws of legal reality : the author's abstract of the diss.... PhD. in Law]. Vladimir, 2006. 26 p. (In Russ.).

13. Filosofiya prava. Kurs lekcij : ucheb. posobie : v 2 t. / otv. red. M. N. Marchenko [Philosophy of law. Course of lectures : study guide : in 2 vol. : ed. by M. N. Marchenko]. Moscow, 2018. Vol. 1.552 p. (In Russ.).

14. Filosofiya ugolovnogo prava / sost. d-r yurid. nauk, prof. YU. V. Golik, A. YU. Golik; red. i vst. st. d-ra yurid. nauk, prof.

YU. V. Golika [The philosophy of criminal law / comp. Dsc. in Law, Prof. Yu. V. Golik, A. Yu. Golik; ed. by Dsc. in Law, Prof. Yu. V. Golik]. St. Petersburg, 2004. 348 p. (In Russ.).

15. CHicherin B. N. Filosofiya prava. 2-e izd., ispr. [Philosophy of law. 2nd ed., rev.]. Moscow, 2011. 344 p. (In Russ.).

16. SHvydkij V. G. Kara - kachestvo ugolovnogo nakazaniya [Scourge - the property of criminal punishment]. Gos-vo i pravo - State and law. 2006. Iss. 4. P. 21-28. (In Russ.). 